\title{
Article \\ Evaluation Schoolyard Wind Comfort Changes Due to Rapid Developments: Case Study of Nanjing, China
}

\author{
Qiuxia $X u^{1}$, Zhen $X u^{1, * \mathbb{B}}$ and Chayn Sun ${ }^{2}$ (D) \\ 1 College of Landscape Architecture, Nanjing Forestry University, Nanjing 210037, China; xuqiuxia@njfu.edu.cn \\ 2 School of Science, RMIT University, Melbourne 3000, Australia; chayn.sun@rmit.edu.au \\ * Correspondence: xuzhen@njfu.edu.cn
}

Citation: Xu, Q.; Xu, Z.; Sun, C. Evaluation Schoolyard Wind Comfort Changes Due to Rapid Developments: Case Study of Nanjing, China. Atmosphere 2022, 13, 43. https://doi.org/10.3390/ atmos13010043

Academic Editors: Qiusheng Li, Junyi $\mathrm{He}$ and Bin $\mathrm{Lu}$

Received: 22 November 2021 Accepted: 24 December 2021 Published: 28 December 2021

Publisher's Note: MDPI stays neutral with regard to jurisdictional claims in published maps and institutional affiliations.

Copyright: (C) 2021 by the authors. Licensee MDPI, Basel, Switzerland. This article is an open access article distributed under the terms and conditions of the Creative Commons Attribution (CC BY) license (https:/ / creativecommons.org/licenses/by/ $4.0 /)$.

\begin{abstract}
Background: Evaluation of wind environments regarding pedestrian comfort may unveil potential hotspot areas, particularly in the context of the rapid urban development in China since the 1990s. (2) Method: With primary schools in Nanjing as case studies, the authors simulated the wind environment of schoolyards with the computational fluid dynamics (CFD) approach and evaluated relevant wind comfort criteria. (3) Results: The study showed that the comfortable wind environment of schoolyards generally expanded in three primary schools in summer and winter, and wind speed and the comfortable wind level decreased in some outdoor schoolyard spaces. The results also indicate that the mean wind speed of the schoolyards did not linearly correlate to the building density either within or outside the schools. An increase in the building height of the primary schools could improve the wind comfort of the schoolyard, but the increased building height in the vicinity may worsen the wind comfort in the schools. Meanwhile, a lift-up or step-shaped building design for schools can improve wind comfort in schoolyards. (4) Conclusions: This study provided simulated results and an approach for urban designers to evaluate and improve the wind environment for school children's outdoor activities.
\end{abstract}

Keywords: wind; primary school; urban form; architectural mass; CFD

\section{Introduction}

Pedestrian wind environment, induced by substantial urban development, has become a major concern in high-density cities in recent decades [1]. One notable wind environment issue involves wind weakening at the pedestrian level, due to overly dense urban planning. This problem has been observed in many regions of the world, and it becomes especially serious in densely built cities at low or mid-latitudes, such as Nanjing, Hongkong, and Tokyo [2]. In the northern mid-latitudes, the data of 822 worldwide surface weather stations has shown that surface wind speeds have declined by $5-15 \%$ from 1979-2008 and the $25-60 \%$ reduction in wind speed stems from the increased surface roughness [3]. The reduced airflow worsens the outdoor thermal comfort of pedestrians, decreases outdoor recreational activities, and amplifies the urban heat island effect [4-6]. Moreover, it has been proven that weak wind allows air pollution to accumulate, which harms the health of urban residents [4]. The epidemics of infectious disease (e.g., SARS, COVID-19) have urged urban designers and policymakers internationally to consider the wind environment in planning residents' living environment [7]. In addition, the construction of skyline structures and high-rise buildings has introduced high-wind velocities around high-rise buildings at the pedestrian level, which could be uncomfortable or even dangerous to pedestrians [8]. Compared with adults, these related problems are more serious for children, due to their vulnerable immune systems and weak heat dissipation $[9,10]$. Thus, to improve wind environment comfort, investigating long-term information on wind environment and the effect of morphological wind changes has become a pressing issue for urban design, especially in regard to schoolyards. 
Students spend about $30 \%$ of their time in school classrooms or schoolyards, which is the main venue for student activity and affects their behavior and health in a variety of ways. Several studies have analyzed that inadequate ventilation in schools is related to high indoor pollutant concentration, lack of learning capacity and increased complaints by the students [11,12]. Baruah et al. [13] assessed the thermal comfort of classrooms in India and concluded that comfort zone varies from 22 to $23.5^{\circ} \mathrm{C}$ in heating periods and 27.3 to $30.7^{\circ} \mathrm{C}$ in cooling periods. However, most of the time the temperature of the classroom does not meet the above requirements because the sole medium for fresh air inside most educational buildings is natural ventilation. As of the above, it becomes evident that a well-ventilated schoolyard is an essential design parameter [14].

Many studies have tried to reveal the precise factors shaping the outdoor wind environment at the pedestrian level, such as building height, shape, arrangements, and density. Du et al. studied the influence of different building heights and porosity sizes on pedestrian-level wind comfort around an isolated building and a group of buildings using computational fluid dynamics (CFD) software [15]. The findings showed that an increase in building height could improve wind comfort for both isolated buildings and groups of buildings, and that larger porosity size improves wind comfort compared to smaller porosity size. Kubota et al. explored the relationship between building density and average wind velocity in 22 actual neighborhoods [16]. Concerning architectural structure, Gao et al. and Yuan et al. proposed that building form variation could improve the wind environment at the pedestrian level $[17,18]$. Most of these studies were conducted to explore the relationships between building environment attributions via simplified and regularly aligned building blocks as urban environment elements or horizontal comparisons of several actual urban situations, but relatively few studies use actual city environments across different time periods. Using these simplified buildings or actual urban spaces during the same time periods can allow for an efficient exploration of significant or insignificant parameters of urban configurations, but it might ignore the complex developmental factors within a real urban space over a long period of time. Considering the rapid development of urban planning and the importance of sustainability considerations in this process, it is essential to assess and analyze the development of urban climates, which could have substantial scientific application in urban development in the future.

Nanjing, a city of 1.79 million inhabitants in eastern China, has a long history of urban planning that extends from the 1920s. Bringing major population and economic growth, the 1990s was a period of rapid change for urban form and infrastructure, leading to abrupt urbanization. Nanjing lacked a comprehensive wind environment plan or quantitative evaluation of the wind environment alongside its rapid development [19]. Primary schools and their surrounding areas have been rebuilt or adjusted in the past 20 years. Thus, primary schools served as good subjects for case studies of urban wind environment change caused by the built environment. In addition, the uncomfortable climatic conditions of summer and winter reduce students' willingness to engage in outdoor activities or physical exertion during these seasons. The wind environment served as an important factor affecting students' comfort in outdoor spaces in summer and winter. Therefore, we selected the wind environment of three primary schools in both summer and winter as representative cases through which to investigate the effects of urban spatial form evolution on the wind environment.

This paper presented the process of wind environment of schoolyards during 20 years in urban areas of Nanjing to explore the influence of urban development. The main objective of this work was not only to quantify the change in the wind environment of schoolyards but also to explore the relationship between changes in wind environment and changes in urban morphology. 


\section{Methods}

\subsection{Study Area}

This study was conducted in the city of Nanjing, China, located at a longitude of $118^{\circ} 22^{\prime} \mathrm{E}$ to $119^{\circ} 14^{\prime} \mathrm{E}$ and a latitude of $31^{\circ} 14^{\prime} \mathrm{N}$ to $32^{\circ} 37^{\prime} \mathrm{N}$. Nanjing has a subtropical monsoon climate with hot summers and cold winters, which serve as representative seasons in Nanjing. The prevailing wind of Nanjing traveled from a south-southeast direction in summer and east-northeast in winter, with an average wind speed of about $3 \mathrm{~m} / \mathrm{s}$.

\subsection{Historical Data of Schoolyards and Their Surrounding Areas}

To examine the aim of the study, three schools (Figure 1, Table 1) were selected for their location in Nanjing. We considered that the wind environment in the target area is affected by the surrounding environment. Regarding the scope of the study areas, the Architecture Institute of Japan proposed that one additional street block should be clearly reproduced to more fully assess the impact of surrounding buildings on the wind environment of the study areas. Based on this standard, this study modeled schoolyards and their adjacent blocks (Figures 2 and 3).

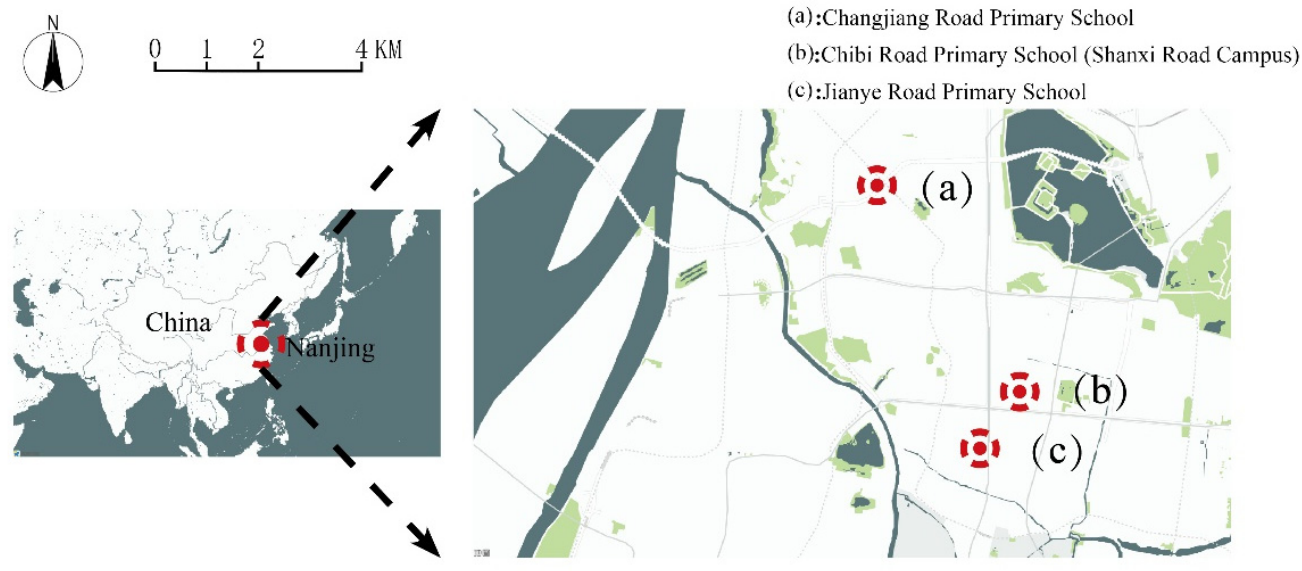

Figure 1. Location of three schools in Nanjing.

Table 1. Characteristics of three schools.

\begin{tabular}{|c|c|c|c|c|c|c|c|}
\hline & \multirow[t]{2}{*}{ School } & \multicolumn{2}{|c|}{ School Area $\left(\mathrm{m}^{2}\right)$} & \multicolumn{2}{|c|}{ Building Density of School (\%) } & \multicolumn{2}{|c|}{$\begin{array}{c}\text { Building Density of } \\
\text { Surrounding Areas (\%) }\end{array}$} \\
\hline & & 1990s & $2010 s$ & 1990s & $2010 s$ & 1990s & 2010s \\
\hline (a) & Changjiang Road Primary School & 11,446 & 9916 & 24 & 25 & 42 & 37 \\
\hline (b) & $\begin{array}{c}\text { Chibi Road Primary School (Shanxi } \\
\text { Road Campus) }\end{array}$ & 4940 & 5212 & 21 & 30 & 30 & 32 \\
\hline (c) & Jianye Road Primary School & 1739 & 5791 & 63 & 27 & 37 & 39 \\
\hline
\end{tabular}

The three schools and their surroundings have undergone the following major changes in the 20 years examined by this study (Figures 2 and 3). The adjacent building on the south of Changjiang Road Primary School was rebuilt from a step-shaped building to a rectangular building. Chibi Road Primary School (Shanxi Road Campus) built a lift-up teaching building. Retaining its original building, Jianye Road Primary School reduced the area of outdoor space in the north, and the demolition of buildings in the south expanded the outdoor space of the schoolyard. Table 1 summarizes the characteristics of the selected schools: school areas, school building density, and surrounding building density. 
$1990 \mathrm{~s}$
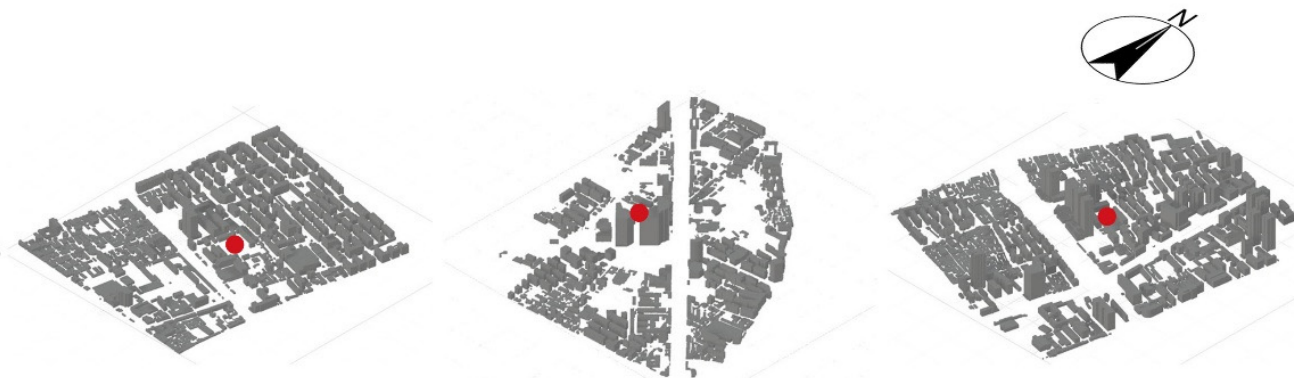

2010 s

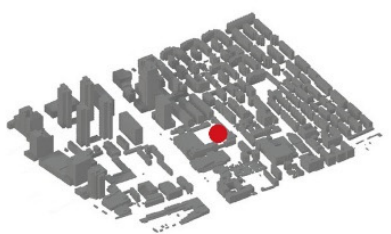

(a)

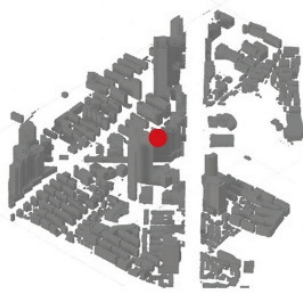

(b)

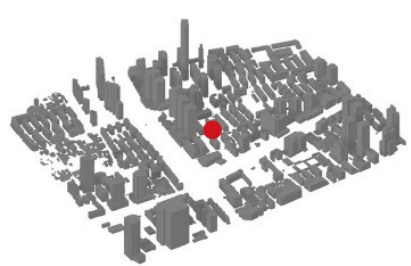

(c)

Figure 2. Bird's-eye view of three schools and surrounding areas in the 1990s and 2010s. (a) Changjiang Road Primary School; (b) Chibi Road Primary School (SR); (c) Jianye Road Primary School.

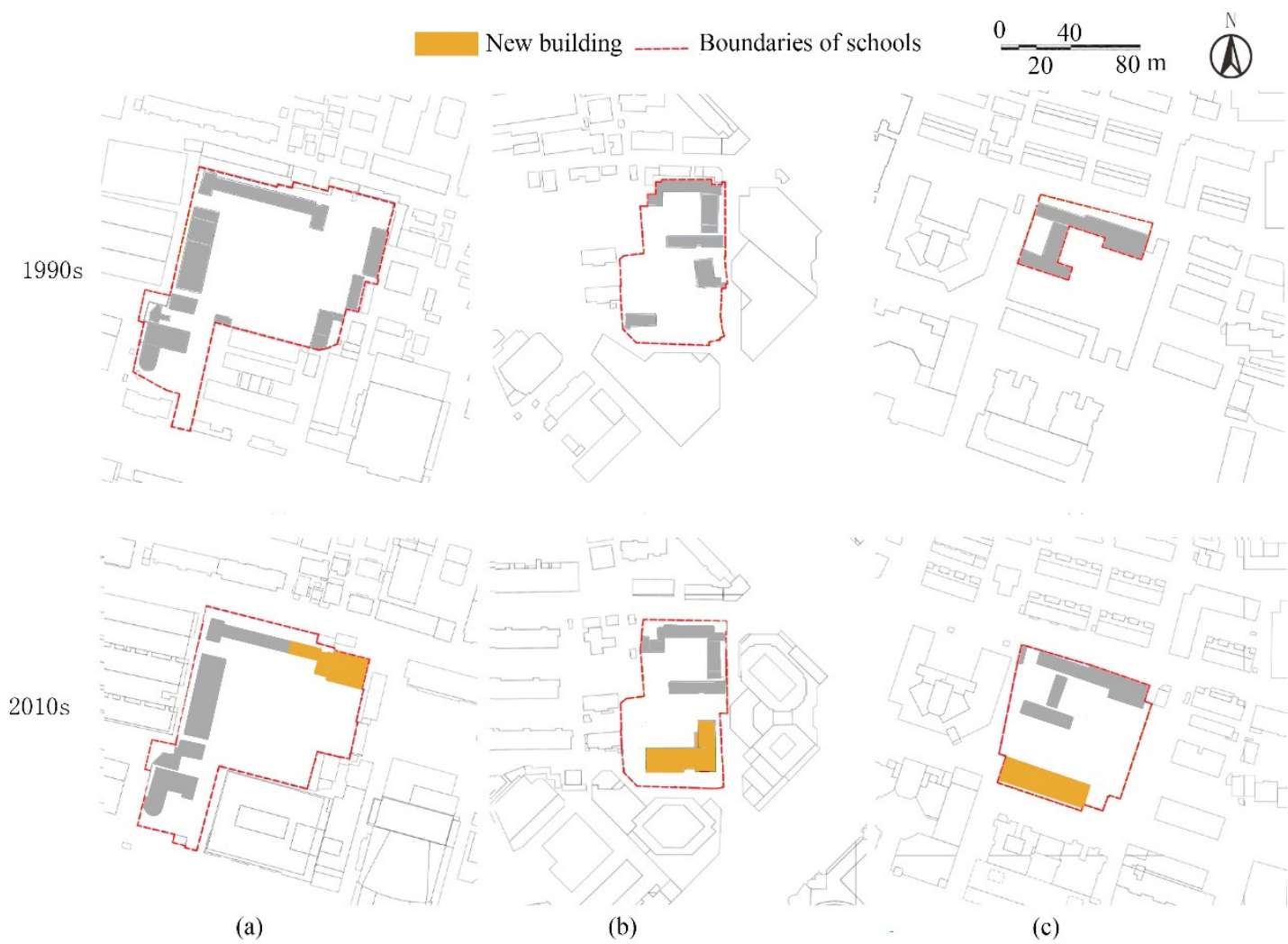

Figure 3. Floor plan of three schools in the 1990s and 2010s. (a) Changjiang Road Primary School; (b) Chibi Road Primary School (SR); (c) Jianye Road Primary School.

\subsection{CFD Modeling}

Wind simulations were conducted using the computer-generated wind tunnel (CWT) software XFlow 2017. XFlow 2017 runs a transient, incompressible flow solver with a finite volume method. Turbulence is solved using a Smagorinsky Large Eddy Simulation (LES) model rather than the Reynolds-averaged Navier-Stokes (RANS) turbulence model, as the LES model has greater accuracy at lower wind speeds compared to the RANS model [20]. 
The computational domain is $1.2 \mathrm{~km} \times 1.2 \mathrm{~km} \times 0.5 \mathrm{~km}$, which follows the Architectural Institute of Japan's (AIJ) guidelines. In order to ensure the simulation accuracy and improve the calculation efficiency, we set the minimum resolved scale of the area close to the building and the ground as $1.5 \mathrm{~m}$ and the maximum resolved scale of the area far from the building and the ground as $6 \mathrm{~m}$. The time step mode is set to fixed automatic and courant is set to 1. Additionally, the length of the model simulation is $550 \mathrm{~s}$ to ensure the stability of wind environment.

Wind speed and direction in Nanjing were based on the wind conditions of the nearest weather station at the Pukou Airport $\left(118.35^{\circ} \mathrm{E}, 32.04^{\circ} \mathrm{N}\right)$, which were obtained from Chinese Standard Weather Data provided by the United States Department of Energy. The wind environment in both periods was simulated with the same prevailing wind of $3 \mathrm{~m} / \mathrm{s}$ from south-southeast in summer and $3 \mathrm{~m} / \mathrm{s}$ from east-northeast in winter (Figure 4 ) so that we could assume that changes in the wind environment were determined completely by the changes in the building environment.

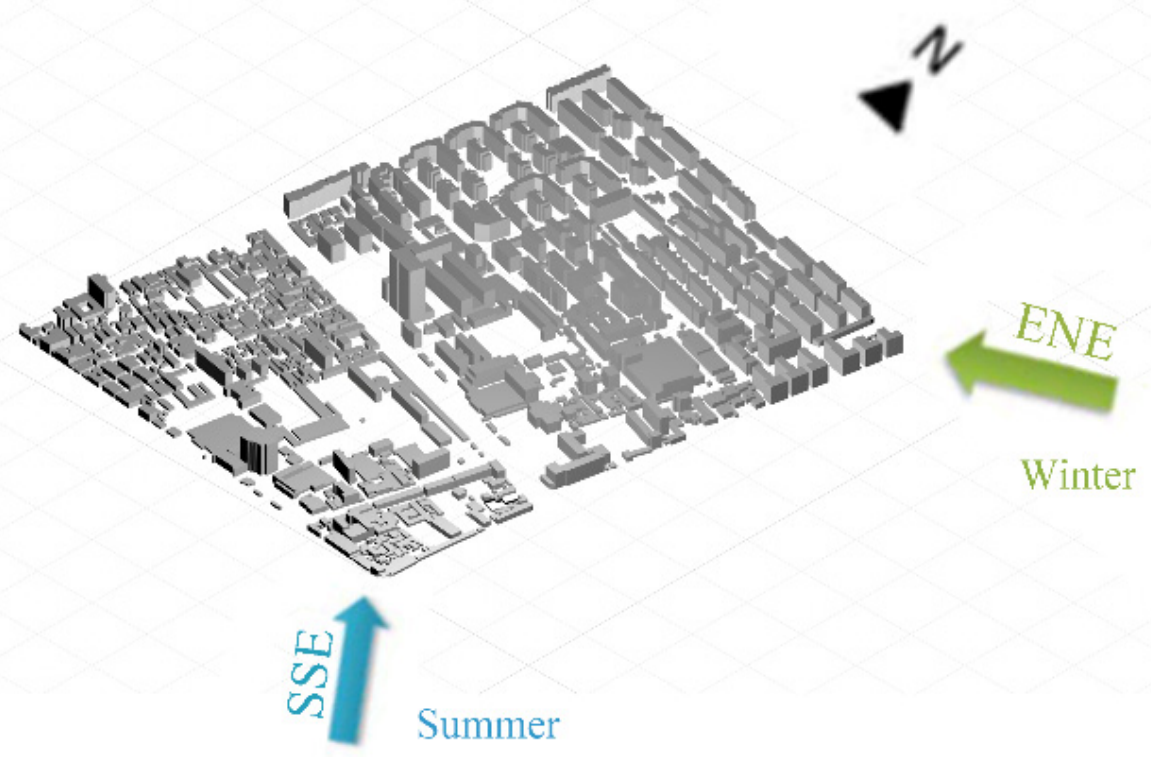

Figure 4. Direction of the winds in the study region.

The building models were reconstructed based on the topographic map provided by government departments. The shapes of the buildings were simplified. Vegetation, small architectural elements (such as billboards, awnings, and bay windows), and street facilities (lamp posts and telephone poles) were omitted from the building model since the records of vegetation and small architectural elements in the 1990s were incomplete, and these elements have relatively little effect on the wind environment in the study area [21].

\subsection{Identification of Pedestrian-Level Wind Comfort}

Due to the different climatic conditions in different regions, there was no uniform threshold value for comfortable wind speed. According to previous research, pedestrian wind comfort involves four primary components: the mechanical force of the wind, the body's thermal comfort, the wind-chill effect, and air pollution. The extensive studies of wind force indicated that the average wind velocity of $5 \mathrm{~m} / \mathrm{s}$ marked the onset of discomfort [22]. Cheng et al. suggested that urban wind speeds $>1 \mathrm{~m} / \mathrm{s}$ are required for securing comfort on typically clear sunny days in summer [23]. Yang et al. indicated that wind speeds of 1-2 m/s are adverse for the human body in winter in Nanjing [24]. Another study showed that air pollution is more difficult to diffuse with wind speeds of less than $1 \mathrm{~m} / \mathrm{s}$ [25]. In this case study, wind comfort assessment performed with those standards for wind comfort and safety was therefore separated into unfavorable, acceptable, and adverse levels (Table 2). 
Table 2. Wind speed table for outdoor comfort in Nanjing.

\begin{tabular}{ccc}
\hline Category & Summer & Winter \\
\hline Unfavorable & $<1 \mathrm{~m} / \mathrm{s}$ & $<1 \mathrm{~m} / \mathrm{s}$ \\
Acceptable & $1 \mathrm{~m} / \mathrm{s} \leq \mathrm{v} \leq 5 \mathrm{~m} / \mathrm{s}$ & $1 \mathrm{~m} / \mathrm{s} \leq \mathrm{v} \leq 2 \mathrm{~m} / \mathrm{s}$ \\
Adverse & $>5 \mathrm{~m} / \mathrm{s}$ & $>2 \mathrm{~m} / \mathrm{s}$ \\
\hline
\end{tabular}

For this study, the pedestrian-level wind speed for the evaluation of wind comfort was selected at $1.2 \mathrm{~m}$ above ground level, since the wind environment of this height was the most closely related to children's activities.

\section{Results and Discussion}

\subsection{Changes of Wind Environment in Summer and Winter}

Table 3 shows the minimum wind speed, maximum wind speed, and average wind speed of three schoolyards in summer which is exported by XFlow 2017 and computed by Excel. From the 1990s to the 2010s, the average wind velocity in Changjiang Road Primary School decreased by $0.09 \mathrm{~m} / \mathrm{s}$ when the average wind speed of Chibi Road Primary School (Shanxi Road Campus) increased significantly. The overall average wind speeds in Jianye Road Primary School showed less change from the 1990s to 2010s. The minimum wind speeds of the outdoor spaces in the three schoolyards were all close to $0 \mathrm{~m} / \mathrm{s}$ in both periods. The maximum wind speed of Chibi Road Primary School (Shanxi Road Campus) decreased, while the maximum wind speed of the other two primary schools increased slightly in the 2010s.

Table 3. Statistics of wind speed at pedestrian level in three primary schools in summer (m/s).

\begin{tabular}{cccccccc}
\hline \multirow{2}{*}{ School } & \multicolumn{3}{c}{ 1990s } & \multicolumn{3}{c}{ 2010s } & \multicolumn{2}{c}{ Mean Wind Speed Change (\%) } \\
\cline { 2 - 7 } & Min & Max & Mean & Min & Max & Mean & -19 \\
\hline Changjiang Road Primary School & 0.00 & 2.20 & 0.47 & 0.00 & 2.35 & 0.38 & +40 \\
Chibi Road Primary School (Shanxi & 0.01 & 3.2 & 0.88 & 0.01 & 2.66 & 1.23 & +1 \\
Road Campus) & 0.04 & 1.48 & 0.84 & 0.01 & 1.58 & 0.85 & \\
Jianye Road Primary School & & & & & &
\end{tabular}

Table 4 shows the pedestrian-level minimum wind speed, maximum wind speed, and average wind speed in winter in the three primary schools during the two periods, based on the average wind speed of the prevailing wind direction (ENE). The average wind speeds in Chibi Road Primary School (Shanxi Road Campus) did not change significantly. In contrast, the average wind speeds increased in Changjiang Road Primary School and Jianye Road Primary School. In summer, the minimum wind speed of the outdoor space of the three schools was similar to that of winter. The maximum wind speed of Jianye Road Primary School increased, while the maximum wind speed of the other two primary schools decreased.

Table 4. Statistics of wind speed at pedestrian level in three primary schools in winter $(\mathrm{m} / \mathrm{s})$.

\begin{tabular}{cccccccc}
\hline \multirow{2}{*}{ School } & \multicolumn{3}{c}{ 1990s } & \multicolumn{3}{c}{ 2010s } & \multicolumn{2}{c}{ Mean Wind Speed Change (\%) } \\
\cline { 2 - 6 } & Min & Max & Mean & Min & Max & Mean & +15 \\
\hline Changjiang Road Primary School & 0.00 & 1.70 & 0.34 & 0.00 & 1.41 & 0.39 & -2 \\
Chibi Road Primary School (Shanxi & 0.02 & 3.28 & 0.91 & 0.01 & 3.18 & 0.89 & +49 \\
Road Campus) & 0.02 & 1.09 & 0.47 & 0.01 & 1.44 & 0.70 & +40 \\
Jianye Road Primary School & & & & & & &
\end{tabular}

The changing trends of average wind speeds in the three primary schools in summer and winter were inconsistent with the study of historical wind speed changes recorded by 
the meteorological station. The results of this study showed that the average wind speeds at the three primary schools increased even more in summer and winter. However, in China, the Netherlands, the Czech Republic, the United States, and Australia, the annual average wind speed declined at $73 \%$ of 822 meteorological stations each decade from 1979 to 2008 [3]. There might be two main reasons for this difference. One is the change in the surroundings of the meteorological stations from open rural areas to an urban environment. The other is the particularity of building forms in these primary schools. Thus, the wind speed of primary schools should be analyzed in combination with the building environment of primary schools, as well as their surrounding areas.

Figures 5 and 6 illustrate the general features of pedestrian-level wind speed distributions in the three primary schools in summer in the 1990s and 2010s. In the 1990s, the south-southeast wind would travel through the building adjacent to Changjiang Road Primary School and enter the northwest activity areas. In the 2010s, the adjacent building, rebuilt from a step-shaped to rectangular design, blocked the south-southeast wind from coming into the outdoor space of Changjiang Road Primary School. Thus, compared to the wind environment of the 1990s, wind speed in the northwest activity area of Changjiang Road Primary School slowed down in the 2010s. A clear difference was observed in wind speed south of Chibi Road Primary School between the 1990s and 2010s. In the 1990s, the summer prevailing wind, accelerated by high-rise buildings, blew into the activity area of Chibi Road Primary School and formed an airflow with a velocity of $3 \mathrm{~m} / \mathrm{s}$ in the middle of the active area. By the 2010s, the new building decreased the wind speed while expanding the area with high wind speed. Figure $5 c$ depicts the wind conditions and the changes of Jianye Road Primary School in the 1990s and 2010s. In the 1990s, Jianye Road Primary School covered a small area, and the wind speed of its outdoor space was 1-2 m/s. In the 2010s, the building to the south of the primary school was demolished to create a new activity area for Jianye Road Primary School. The additional activity area was directly exposed to southeast winds, with wind speeds of $1-2 \mathrm{~m} / \mathrm{s}$.

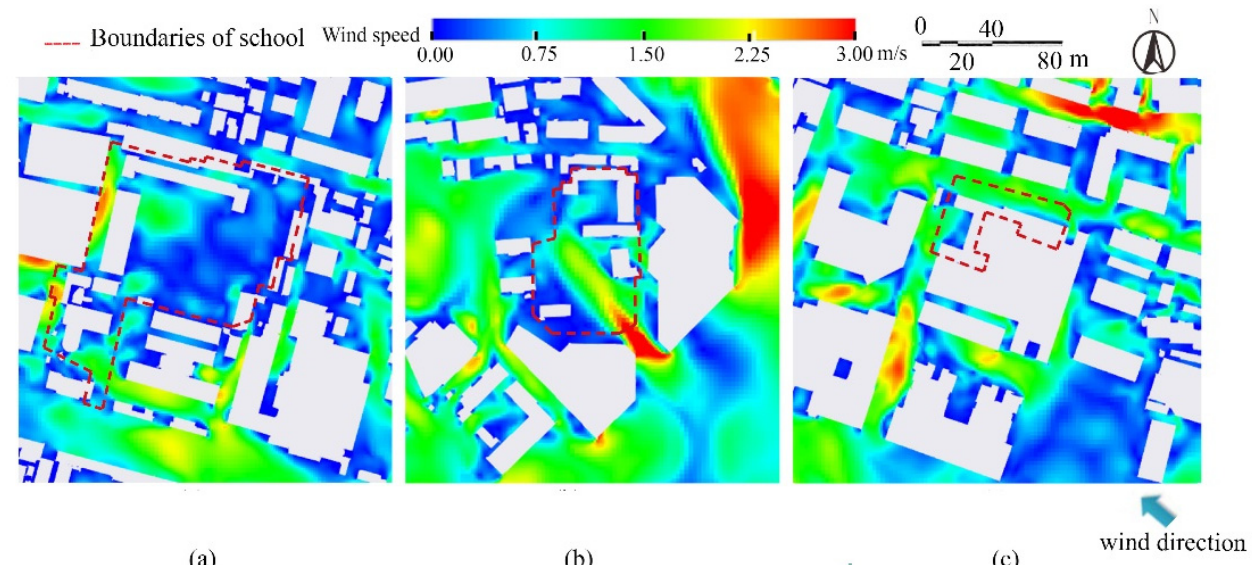

Figure 5. Wind speed distributions at the pedestrian level in three primary schools in summer in the 1990s: (a) Changjiang Road Primary School; (b) Chibi Road Primary School (Shanxi Road Campus); (c) Jianye Road Primary School.

Figures 7 and 8 illustrate the wind environment of three schoolyards at the pedestrian level in winter in the 1990s and 2010s. In winter, similar to in summer, the reconstruction of buildings led the wind speed at the gate of Changjiang Road Primary School to slow down in the 2010s, compared with the 1990s. In the winter of the 1990s and 2010s, the buildings of Chibi Road Primary School (Shanxi Road Campus) blocked east-northeast winds from entering the eastern part of the schoolyard. However, the wind speed in the south of the schoolyard during both periods was 1-2 m/s. For Jianye Road Primary School, the wind speeds of the original outdoor spaces were lower in both periods. However, in the 2010s, 
east-northeast winds that run along low buildings were inducted into the new outdoor spaces with higher wind speeds than in the 1990s.

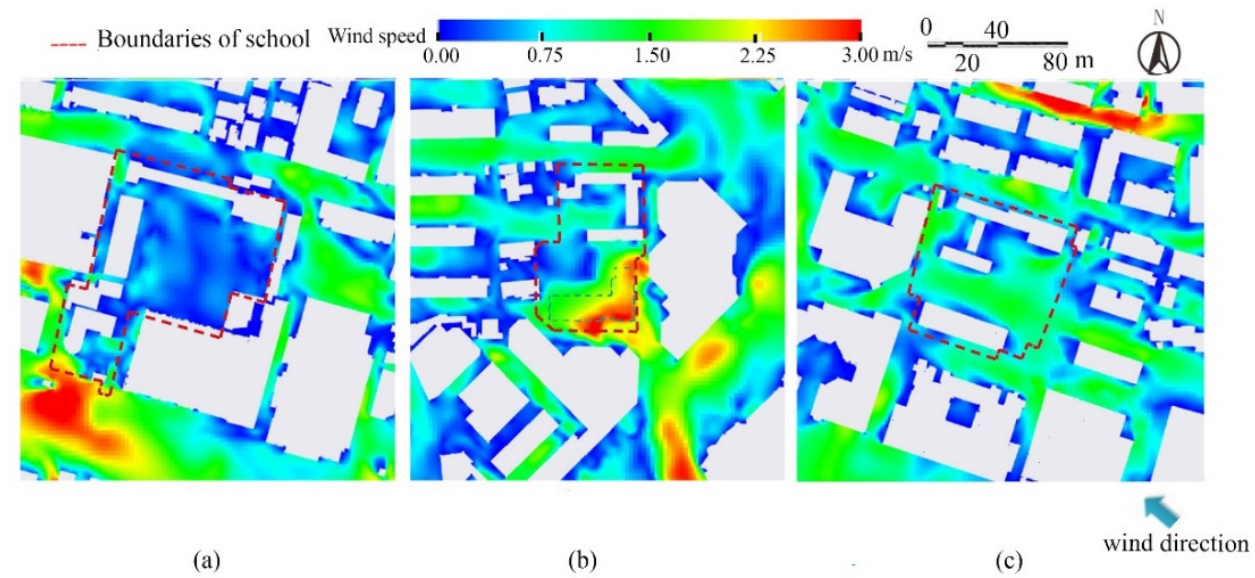

Figure 6. Wind speed distributions at the pedestrian level in three primary schools in summer in the 2010s: (a) Changjiang Road Primary School; (b) Chibi Road Primary School (Shanxi Road Campus); (c) Jianye Road Primary School.

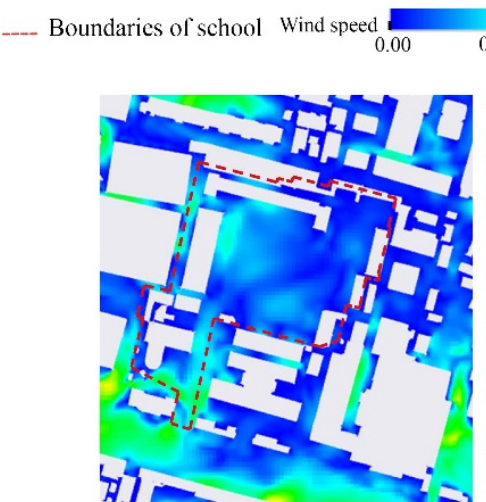

(a)

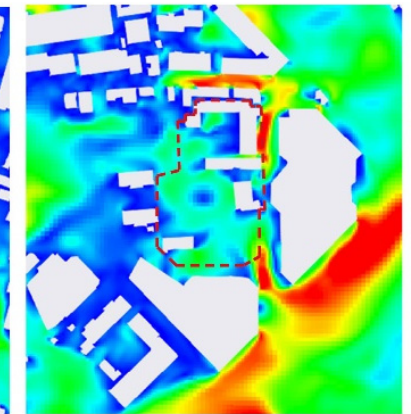

(b)
(1) wind direction

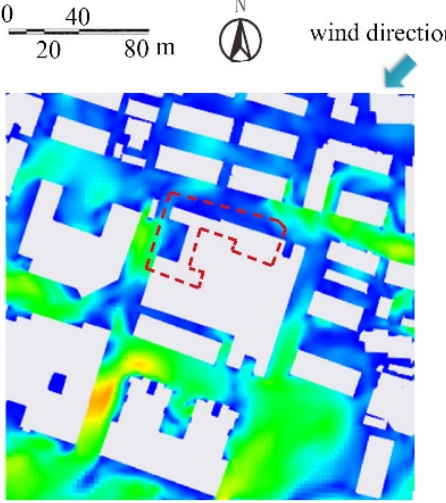

(c)

Figure 7. Wind speed distributions at the pedestrian level in three primary schools in winter in the 1990s: (a) Changjiang Road Primary School; (b) Chibi Road Primary School (Shanxi Road Campus); (c) Jianye Road Primary School.

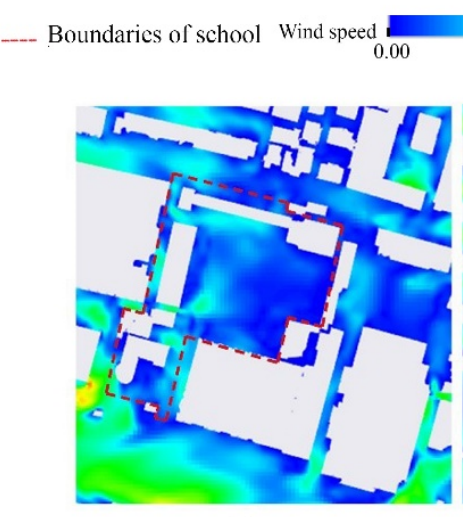

(a)

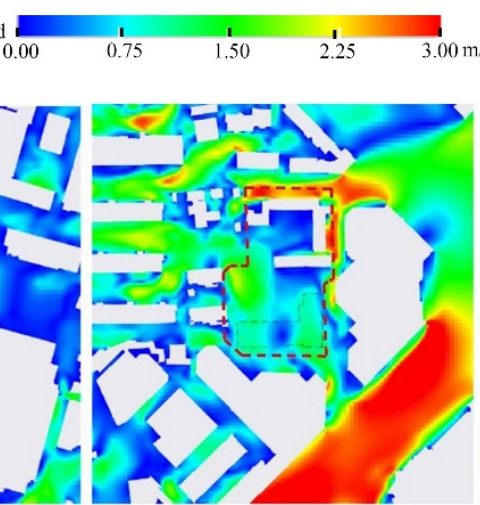

(b)

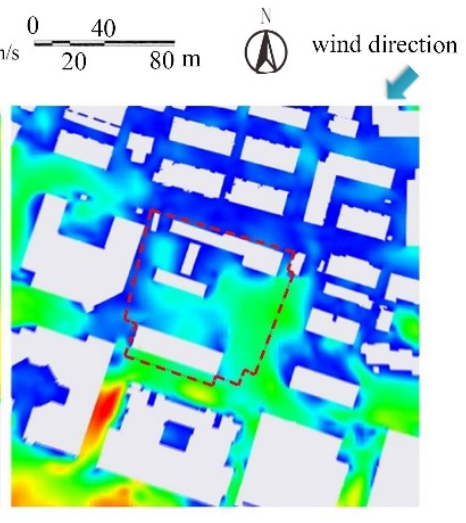

(c)

Figure 8. Wind speed distributions at the pedestrian level in three primary schools in winter in the 2010s: (a) Changjiang Road Primary School; (b) Chibi Road Primary School (Shanxi Road Campus); (c) Jianye Road Primary School. 


\subsection{Changes in Wind Comfort in Summer and Winter}

The pedestrian-level wind comfort of the three primary schools in summer in the 1990s and 2010s is shown in Figures 9 and 10. The areas with acceptable wind comfort at the three primary schools occupied a small proportion of these facilities in the summers and winters of the 1990s and 2010s. In summer during the 1990s, 1-40\% of outdoor space was suitable for children's outdoor activities. And in the summers of the $2010 \mathrm{~s}, 3-57 \%$ of outdoor spaces had acceptable wind comfort at the pedestrian level. We can observe that the wind comfort and average wind speed of these primary schools changed through similar trends in the 1990s and 2010s. The acceptable wind comfort increased at Chibi Road Primary School and Jianye Road Primary School, while it decreased at Changjiang Road Primary School. Although the general trend of the three primary schools in summer was an increase in wind comfort, some outdoor schoolyard spaces had changed from having comfortable winds to unfavorable winds.

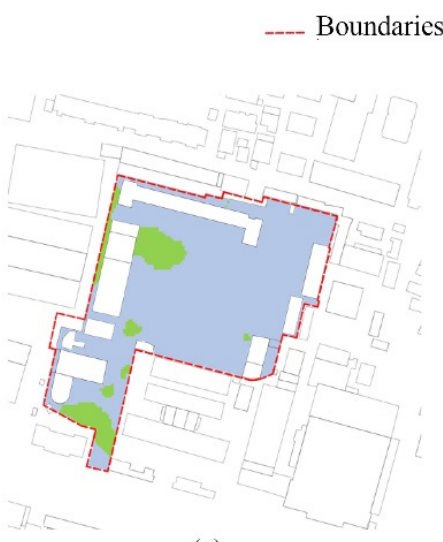

(a)
Unfavorable area

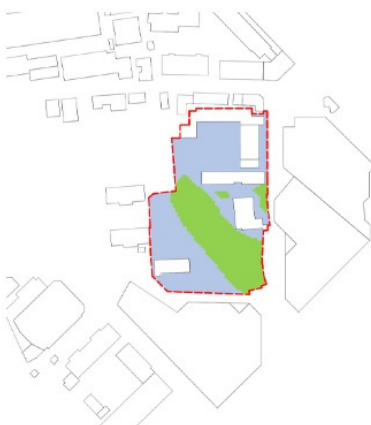

(b)
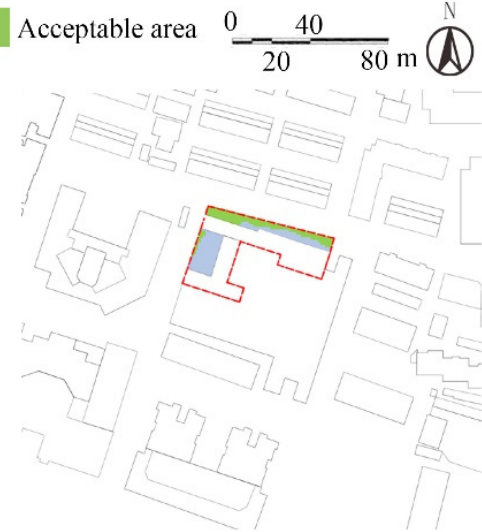

(c)

Figure 9. Distribution of wind comfort zones at the pedestrian level at three primary schools in summer in the 1990s: (a) Changjiang Road Primary School; (b) Chibi Road Primary School (Shanxi Road Campus); (c) Jianye Road Primary School.

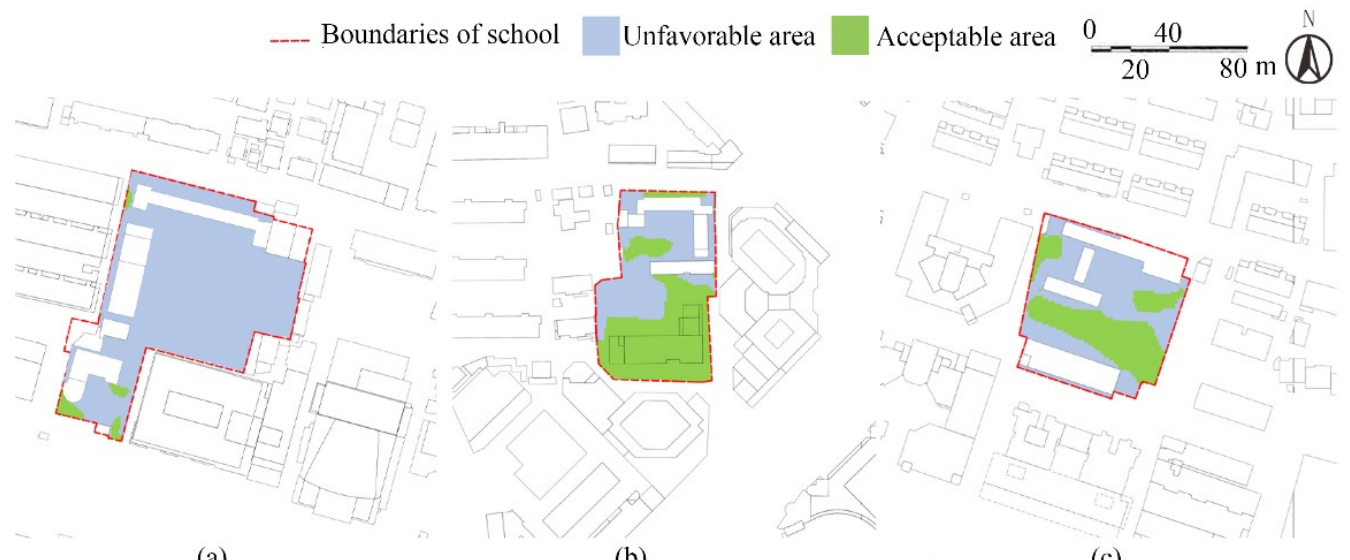

(a)

(b)

(c)

Figure 10. Distribution of wind comfort zones at the pedestrian level at three primary schools in summer in the 2010s: (a) Changjiang Road Primary School; (b) Chibi Road Primary School (Shanxi Road Campus); (c) Jianye Road Primary School.

Figures 11 and 12 show the pedestrian-level wind comfort of the three primary schools in winter in the 1990s and 2010s. As in summer, the acceptable area of Changjiang Road Primary School was also decreasing at the school gate in the winter in the 2010s. In the 1990s, the adverse area of Chibi Road Primary School (Shanxi Road Campus) was small, located in an area on the edge of campus not used for activities. However, in the 2010s, 
there was a small area of tolerance in the student activity area, which might cause students to feel cold during activities in this area. In addition, although this school's acceptable area spaces were located in the south of the campus, their shape had changed by this point due to changes to the building form. Regarding Jianye Road Primary School, the acceptable area had increased due to the expansion of the school area.

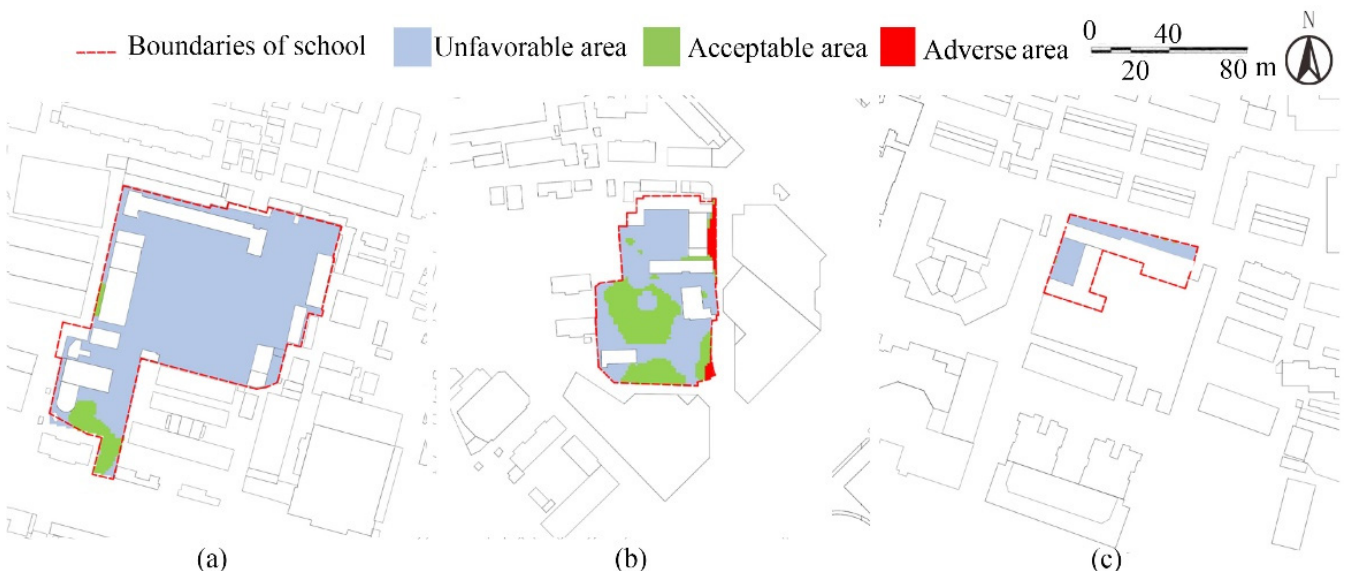

Figure 11. Distribution of wind comfort zones at the pedestrian level in three primary schools in winter in the 1990s: (a) Changjiang Road Primary School; (b) Chibi Road Primary School (Shanxi Road Campus); (c) Jianye Road Primary School.

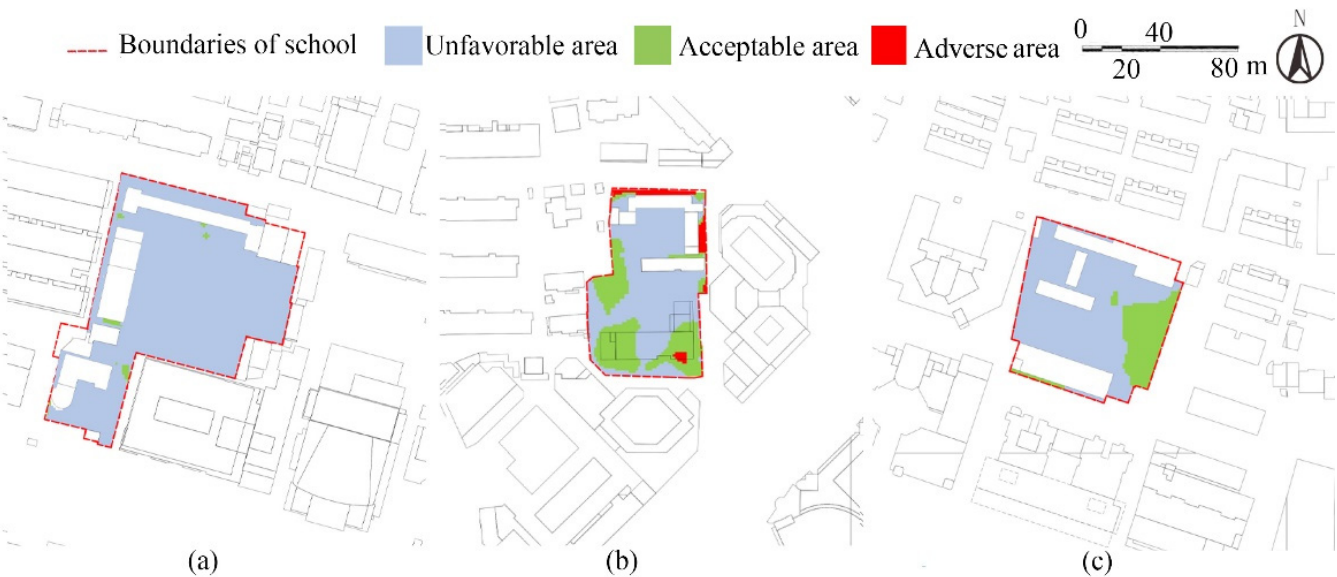

Figure 12. Distribution of wind comfort zones at the pedestrian level in three primary schools in winter in the 2010s: (a) Changjiang Road Primary School; (b) Chibi Road Primary School (Shanxi Road Campus); (c) Jianye Road Primary School.

\subsection{The Effect of School and Surrounding Area Morphology}

In order to study and understand how the morphology of schools and surrounding areas affect ventilation conditions, relationships between the change in morphological parameters of schools and surrounding areas and the average pedestrian-level wind speed changes of schoolyards were analyzed. Figure 13a,b shows the relationships between building density change in schools and blocks and the average wind speed change of schoolyards at the pedestrian level. The more building density increased in a school and its block, the greater the ventilation capacity of the primary school. This finding differed from the results of previous cross-sectional studies that found that an increase in the building coverage ratio decreased the mean wind velocity [12]. Bourbia et al. found that areas of the same density with different textural forms can exhibit different microclimate performances [26]. The observation of actual primary schools and blocks in the current study revealed that pedestrian wind speed depends not only on building density but also building height and the frontal area index. Therefore, combining multiple morphological 
parameters served as an appropriate way to define the pedestrian wind speed under the actual urban conditions.

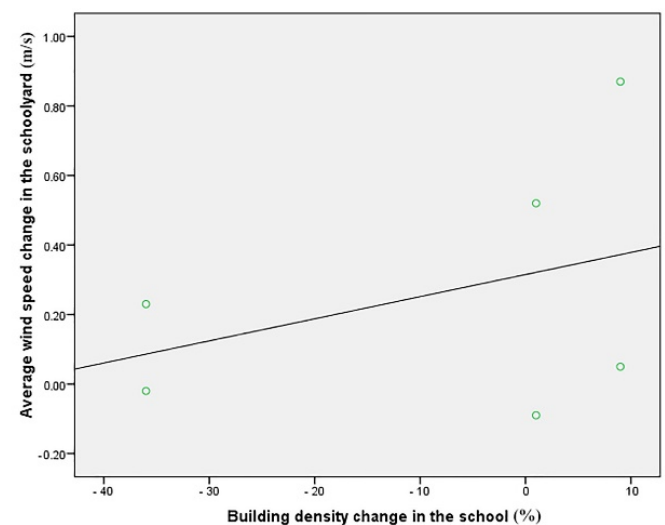

(a)

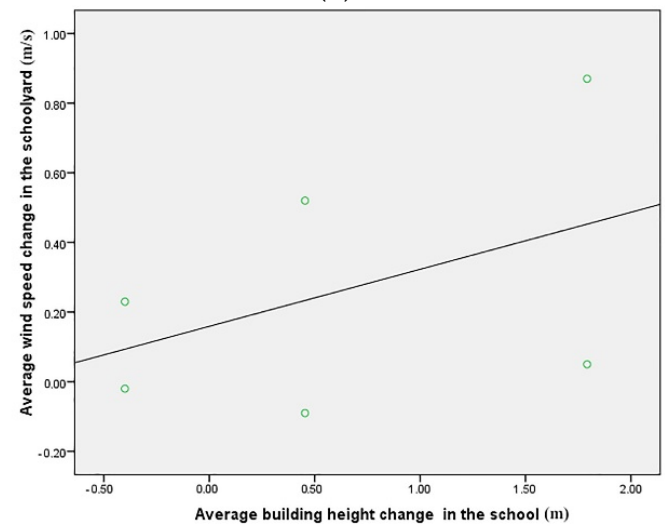

(c)

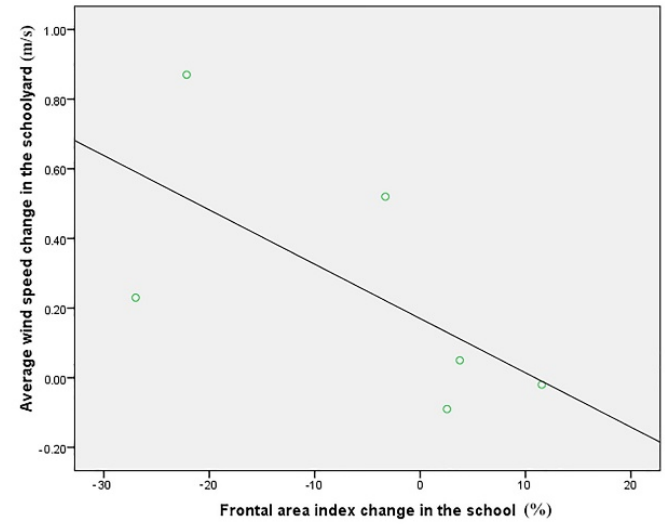

(e)

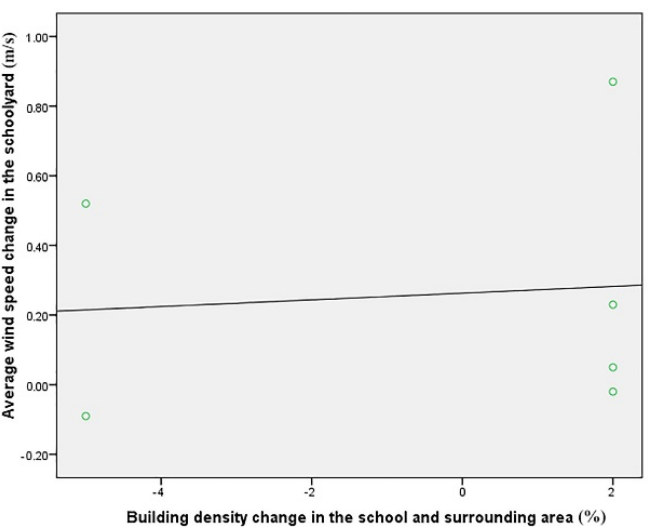

(b)

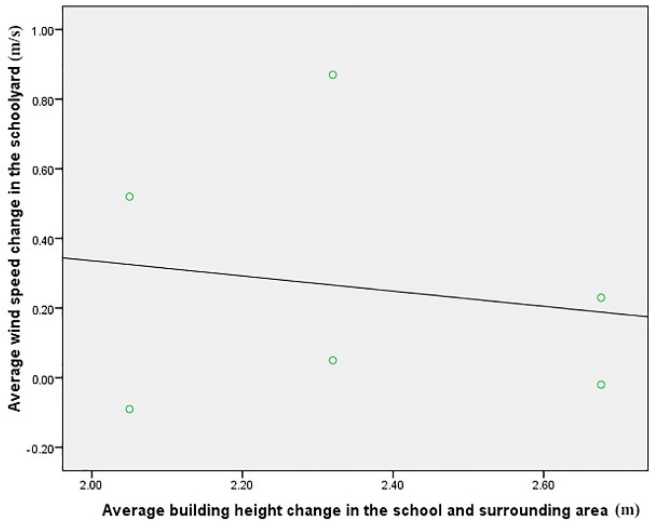

(d)

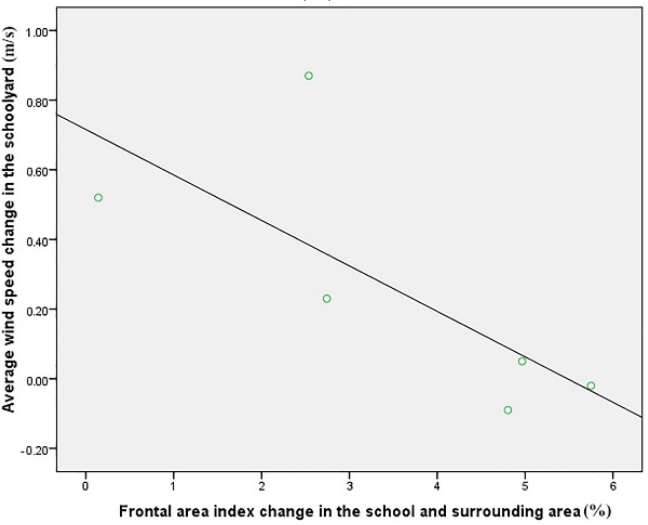

(f)

Figure 13. Relationship between the change of morphological parameters and mean pedestrian-level wind speed: $(\mathbf{a}-\mathbf{f})$.

Figure $13 c, d$ showed the relationships between the change in the average building heights of the school and its block and the average wind speed change of the schoolyards in summer and winter. The average building height in schools positively correlated with the mean wind speed in schools, which has been extensively proven [15], but the negative correlation between average building height of the surrounding environment and the mean pedestrian-level wind speed has been less studied. The increase in school building heights caused the corner effect, which increased the wind speed at the corners of schools [1]. However, increasing the building height of the block might decrease the airflow entering 
the outdoor spaces of primary schools, which might in turn result in a decrease in the average wind speed [21].

Figure 13e,f shows the relationship between the frontal area index changes and the mean pedestrian-level wind speed at the three primary schools and surrounding areas in summer and winter. The frontal area index is the ratio of the total area of building facets projected to plane normal facing the particular wind direction to the plane area $[27,28]$. It can be seen that the frontal area indexes in schools and blocks negatively correlated with the mean pedestrian-level wind speed, consistent with the findings of a study in Hongkong, China [29]. The frontal area index, calculated based on the specific wind direction, served as a comprehensive morphological parameter that combined the average building height, width, and density [30]. Thus, it might have a greater influence on the average campus wind speed than other morphological parameters.

\subsection{Effect of the Architectural Form}

Architectural form and associated urban development play an important role in the change of the wind environment. At Changjiang Road Primary School, the adjacent building to the south of the school was rebuilt from a stepped to rectangular design, although the height remained the same (Figure 14). This rectangular building type has been widely adopted for commercial and public buildings by architects in recent decades. As shown in Figures 9-11 and 12a, in summer and winter, pedestrian wind comfort decreased in the activity area and the school gate area, which were on the leeward side of the rebuilt building. This reflected that although the heights of the two buildings were the same, the step-shaped building induced the faster winds traveling across the top of the building to move down to the pedestrian-level space, making the design more favorable for pedestrianlevel ventilation (Figure 14). As an enclosed or semi-enclosed space, the ratio of the top width $(\mathrm{W})$ of the schoolyard to the height of the windward building $(\mathrm{H})$ has a significant influence on its wind environment [31]. We found that when $\mathrm{W} / \mathrm{H}$ was less than 5 , the airflow above was unlikely to enter the enclosed or semi-enclosed space. The change from the stepped shape to the rectangular shape of the adjacent building actually reduced the width of the above outside space, while the height remained unchanged.

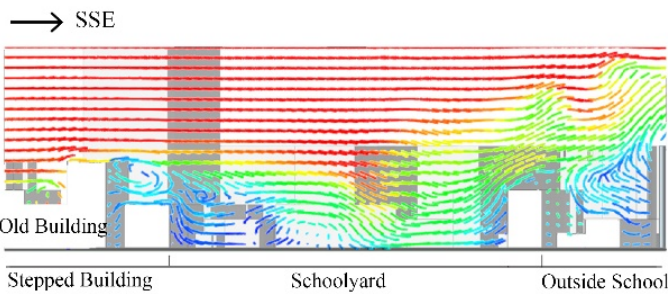

(a)

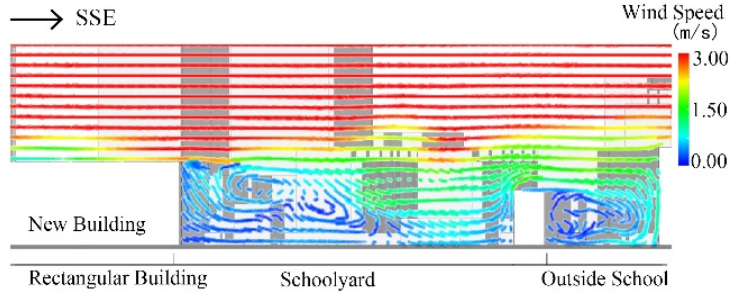

(b)

Figure 14. The north-south wind section of Changjiang Road Primary School in summer: (a) 1990s; (b) 2010s. As shown in Figures 15 and 16, the new lift-up style teaching building was constructed at Shanxi Road Primary School to provide more teaching room for students. This building form provides students with partly shaded space and classrooms. Consequently, the lift-up building served as an attractive way for school managers and designers to provide outdoor spaces and added teaching rooms in high-density cities [32]. As shown in Figure 16a,b, compared with the wind environment in the 1990s, the wind comfort area expanded at the bottom of the lift-up building in the 2010s. To verify the benefits of this architectural form for the pedestrian-level wind environment, the wind environments of the lift-up building and non-lift-up building in Shanxi Road Primary School were simulated. As shown in Figure 16b,c, the pedestrian-level wind of Shanxi Road Primary School with a non-lifted building weakened on the leeward side of the building in the summer. This indicated that the lifted building design could reduce the building's obstruction of pedestrian-level airflow. In the winter, however, the lift-up design did not enhance the wind speed around the building, showing that the improvement to the pedestrian-level horizontal wind speed by the overhead layer related to the wind direction [8]. 


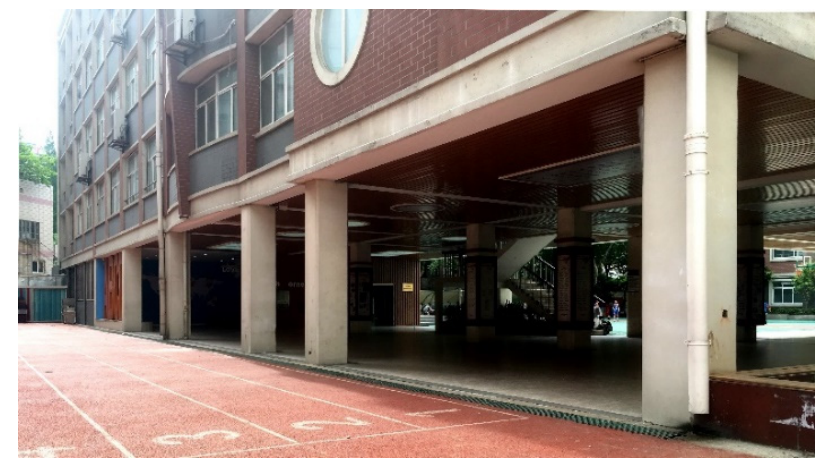

Figure 15. The lift-up building in Chibi Road Primary School (Shanxi Road Campus).

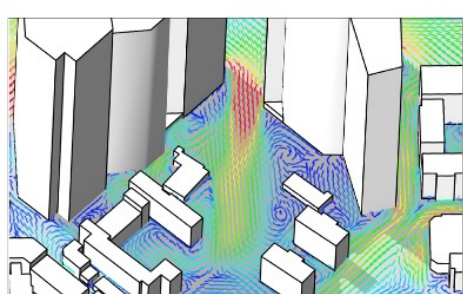

(a)

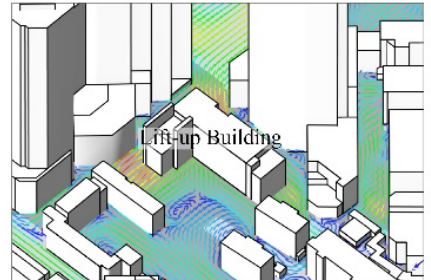

(b)

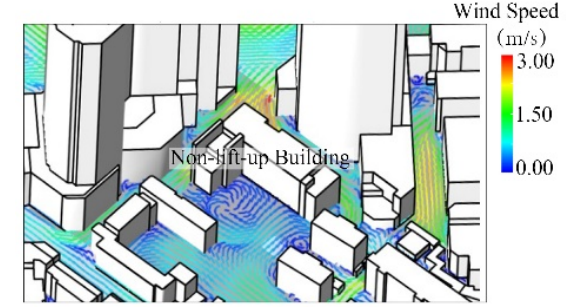

(c)

Figure 16. The wind environment of Chibi Road Primary School (Shanxi Road Campus) in summer: (a) 1990s; (b) 2010s; (c) no-lift-up building scenario simulation in the 2010s.

\section{Conclusions}

This study investigated the effects of changes in morphological characteristics of the schoolyards and their surroundings on the pedestrian-level wind environment over the past two decades. The findings of this study revealed the complexity of urban morphology and wind environment. During these two decades of urban development, in summer and winter, the wind environment of some schoolyards improved, while that of some schoolyards deteriorated, which depended on the building environment of primary schools and surrounding blocks.

As for school and block morphology, it was unreasonable to improve the average wind speeds of primary schools by controlling the building density of schools and their blocks, since wind speed change may be affected by other factors such as building height. For building height, average wind speed in primary schools was higher when the average building height was higher, and the average building height of the block was lower. Regarding the frontal area index, the mean wind speeds in primary schools were weakened by increasing the frontal area index of primary schools and their blocks. Different forms of buildings in the primary schools or adjacent buildings had different levels of resistance to airflow, which had different effects on the wind environment at pedestrian height. The results showed that a lift-up building design aided in improving pedestrian wind comfort in primary schools. However, this effect of the wind environment related to the angle between the wind direction and the lift-up building design. Further, at the same building height, the pedestrian-level wind shadow area created by the step-shaped building design was smaller, which enhanced wind comfort at the pedestrian level.

The results of this study provided evidence and useful lessons for improving pedestrianlevel wind comfort in urban development. The findings will help urban designers to improve wind comfort in schools from a long-term perspective through architectural forms and urban morphology. These findings not only pertain to the outdoor spaces of primary schools, but also have important implications for the wind environment of open spaces used by the public. 


\begin{abstract}
Author Contributions: Conceptualization, Z.X.; methodology, Z.X. and Q.X.; software, Q.X.; validation, Q.X., Z.X. and C.S.; formal analysis, Q.X.; investigation, Q.X.; resources, Z.X.; data curation, Q.X.; writing—original draft preparation, Q.X.; writing—review and editing, Z.X. and C.S.; visualization, Q.X.; supervision, Z.X.; project administration, Z.X.; funding acquisition, Z.X. All authors have read and agreed to the published version of the manuscript.
\end{abstract}

Funding: This research was funded by Humanity and Social Science Foundation of Ministry of Education (18YJCZH043), National Natural Science Foundation of China (52078254, 31971721) and Priority Academic Program Development of Jiangsu Higher Education Institutions (PAPD).

Institutional Review Board Statement: Not applicable.

Informed Consent Statement: Not applicable.

Data Availability Statement: Not applicable.

Acknowledgments: The author would like to thank anonymous reviewers for their helpful comments on this article, Lingyun Han for her suggestions on research design and funding support, and Anqi Liu for her assistance.

Conflicts of Interest: The authors declare no conflict of interest.

\title{
References
}

1. Peng, L.; Liu, J.P.; Wang, Y.; Chan, P.W.; Lee, T.C.; Peng, F.; Li, Y.G. Wind weakening in a dense high-rise city due to over nearly five decades of urbanization. Build. Environ. 2018, 138, 207-220. [CrossRef]

2. $\mathrm{Ng}$, E. Policies and technical guidelines for urban planning of high-density cities-Air ventilation assessment (AVA) of Hong Kong. Build. Environ. 2009, 44, 1478-1488. [CrossRef]

3. Vautard, R.; Cattiaux, J.; Yiou, P.; Thepaut, J.N.; Ciais, P. Northern hemisphere atmospheric stilling partly attributed to an increase in surface roughness. Nat. Geosci. 2010, 3, 756-761. [CrossRef]

4. Liu, Z.R.; Hu, B.; Wang, L.L.; Wu, F.K.; Gao, W.K.; Wang, Y.S. Seasonal and diurnal variation in particulate matter (PM 10 and $\mathrm{PM}_{2.5}$ ) at an urban site of Beijing: Analyses from a 9-year study. Environ. Sci. Pollut. Res. 2015, 22, 627-642. [CrossRef]

5. Nikolopoulou, M.; Lykoudis, S. Use of outdoor spaces and microclimate in a Mediterranean urban area. Build. Environ. 2007, 42, 3691-3707. [CrossRef]

6. Oke, T.R. City size and the urban heat island. Atmos. Environ. 1967 1973, 7, 769-779. [CrossRef]

7. Ahmadi, M.; Sharifi, A.; Dorosti, S.; Ghoushchi, S.J.; Ghanbari, N. Investigation of effective climatology parameters on COVID-19 outbreak in Iran. Sci. Total Environ. 2020, 729, 7. [CrossRef]

8. Mittal, H.; Sharma, A.; Gairola, A. A review on the study of urban wind the pedestrian level around buildings. J. Build. Eng. 2018, 18, 154-163. [CrossRef]

9. Falk, B. Effects of thermal stress during rest and exercise in the paediatric population. Sports Med. 1998, 25, 221-240. [CrossRef]

10. Vanos, J.K. Children's health and vulnerability in outdoor microclimates: A comprehensive review. Environ. Int. 2015, 76, 1-15. [CrossRef]

11. Santamouris, M.; Synnefa, A.; Asssimakopoulos, M.; Livada, I.; Pavlou, K.; Papaglastra, M.; Gaitani, N.; Kolokotsa, D.; Assimakopoulos, V. Experimental investigation of the air flow and indoor carbon dioxide concentration in classrooms with intermittent natural ventilation. J. Phys. Chem. C 2008, 113, 1833-1843. [CrossRef]

12. Heracleous, C.; Michael, A. Thermal comfort models and perception of users in free-running school buildings of eastmediterranean region. Energy Build. 2020, 215, 109912. [CrossRef]

13. Baruah, P.; Singh, M.K.; Mahapatra, S. Thermal Comfort in Naturally Ventilated Classrooms. In Proceedings of the 30th International Plea Conference, Ahmedabad, India, 16-18 December 2014.

14. Heracleous, C.; Michael, A. Experimental assessment of the impact of natural ventilation on indoor air quality and thermal comfort conditions of educational buildings in the eastern mediterranean region during the heating period. J. Build. Eng. 2019, 26, 100917. [CrossRef]

15. Du, Y.; Mak, C.M.; Tang, B.S. Effects of building height and porosity on pedestrian level wind comfort in a high-density urban built environment. Build. Simul. 2018, 11, 1215-1228. [CrossRef]

16. Kubota, T.; Miura, M.; Tominaga, Y.; Mochida, A. Wind tunnel tests on the relationship between building density and pedestrianlevel wind velocity: Development of guidelines for realizing acceptable wind environment in residential neighborhoods. Build. Environ. 2008, 43, 1699-1708. [CrossRef]

17. Gao, Y.; Yao, R.; Li, B.; Turkbeyler, E.; Luo, Q.; Short, A. Field studies on the effect of built forms on urban wind environments. Renew. Energy 2012, 46, 148-154. [CrossRef]

18. Yuan, C.; $\mathrm{Ng}$, E. Building porosity for better urban ventilation in high-density cities-A computational parametric study. Build. Environ. 2012, 50, 176-189. [CrossRef]

19. Xu, Z.; Han, L.Y. The historical changes of winds above open spaces and the surroundings of Nanjing. Urban Plan. Forum 2018, $242,81-88$. 
20. Blocken, B.; Stathopoulos, T.; van Beeck, J.P.A.J. Pedestrian-level wind conditions around buildings: Review of wind-tunnel and CFD techniques and their accuracy for wind comfort assessment. Build. Environ. 2016, 100, 50-81. [CrossRef]

21. Kim, H.; Macdonald, E. Wind and the city: An evaluation of San Francisco's planning approach since 1985. Environ. Plan. B Urban Anal. City Sci. 2016, 44, 10-32. [CrossRef]

22. Soligo, M.J.; Irwin, P.A.; Williams, C.J.; Schuyler, G.D. A comprehensive assessment of pedestrian comfort including thermal effects. J. Wind. Eng. Ind. Aerodyn. 1998, 77, 753-766. [CrossRef]

23. Cheng, V.; Ng, E. Thermal comfort in urban open spaces for Hong Kong. Archit. Sci. Rev. 2006, 49, 236-242. [CrossRef]

24. Yang, J.; Zhang, T.; Fu, X. Coupling Mechanism between Wind Environment and Spatial Form and Optimization Design in Urban Center; Southeast University Press: Nanjing, China, 2016; pp. 37-65.

25. Li, H.; Guo, B.; Han, M.; Tian, M.; Zhang, J. Particulate matters pollution characteristic and the correlation between $\mathrm{PM}_{(\mathrm{PM}} \mathrm{P}_{2.5}$ $\mathrm{PM}_{10}$ ) and meteorological factors during the summer in Shijiazhuang. J. Environ. Prot. 2015, 6, 457. [CrossRef]

26. Bourbia, F.; Boucheriba, F. Impact of street design on urban microclimate for semiarid climate (Constantine). Renew. Energy 2010, 35, 343-347. [CrossRef]

27. Man, S.W.; Niched, J.E.; To, P.H.; Wang, J. A simple method for designation of urban ventilation corridors and its application to urban heat island analysis. Build. Environ. 2010, 45, 1880-1889.

28. Ernest, R.; Ford, B. The role of multiple-courtyards in the promotion of convective cooling. Archit. Sci. Rev. 2012, 55, 241-249. [CrossRef]

29. Ng, E.; Yuan, C.; Chen, L.; Ren, C.; Fung, J.C. Improving the wind environment in high-density cities by understanding urban morphology and surface roughness: A study in Hong Kong. Landsc. Urban Plan. 2011, 101, 59-74. [CrossRef] [PubMed]

30. Raupach, M.R. Drag and drag partition on rough surfaces. Bound.-Layer Meteorol. 1992, 60, 375-395. [CrossRef]

31. Moonen, P.; Dorer, V.; Carmeliet, J. Evaluation of the ventilation potential of courtyards and urban street canyons using RANS and LES. J. Wind. Eng. Ind. Aerodyn. 2011, 99, 414-423. [CrossRef]

32. Niu, J.; Liu, J.; Lee, T.C.; Lin, Z.; Mak, C.; Tse, K.T.; Kwok, K.C.S. A new method to assess spatial variations of outdoor thermal comfort: Onsite monitoring results and implications for precinct planning. Build. Environ. 2015, 91, 263-270. [CrossRef] 